\title{
Oxygen transfer and mixing in mechanically agitated airlift bioreactors
}

\author{
Yusuf Chisti $^{\mathrm{a}, *}$, Ulises J. Jauregui-Haza ${ }^{\mathrm{b}}$ \\ ${ }^{a}$ Institute of Technology and Engineering, Massey University, Private Bag 11-222, Palmerston North, New Zealand \\ ${ }^{\mathrm{b}}$ Centro de Química Farmacéutica, 200 y 21 Atabey, Aptdo. 16042, Havana, Cuba
}

Received 12 April 2001; accepted after revision 6 November 2001

\begin{abstract}
Gas holdup, mixing, liquid circulation and gas-liquid oxygen transfer were characterized in a large $\left(\sim 1.5 \mathrm{~m}^{3}\right)$ draft-tube airlift bioreactor agitated with Prochem ${ }^{\circledR}$ hydrofoil impellers placed in the draft-tube. Measurements were made in water and in cellulose fiber slurries that resembled broths of mycelial microfungi. Use of mechanical agitation generally enhanced mixing performance and the oxygen transfer capability relative to when mechanical agitation was not used; however, the oxygen transfer efficiency was reduced by mechanical agitation. The overall volumetric gas-liquid mass transfer coefficient declined with the increasing concentration of the cellulose fiber solids; however, the mixing time in these strongly shear thinning slurries was independent of the solids contents $(0-4 \% \mathrm{w} / \mathrm{v})$. Surface aeration never contributed more than $12 \%$ to the total mass transfer in air-water. (C) 2002 Elsevier Science B.V. All rights reserved.
\end{abstract}

Keywords: Bioreactors; Hydrofoil impellers; Airlift bioreactors; Mixing; Aeration; Surface aeration

\section{Introduction}

Airlift bioreactors and mechanically stirred tanks are widely used in bioprocessing [1,2]. Airlift bioreactors are useful with relatively less viscous fluids and when there is a need for gentle agitation [3] and low-cost oxygen transfer [4,5]. In comparison, conventional stirred fermenters have a broader range of applications but they perform poorly in highly viscous non-Newtonian media, have a poorly defined mixing pattern relative to airlift reactors, and cannot be aerated at a high rate because of impeller flooding. A mechanically stirred hybrid airlift bioreactor with one or more downward pumping axial flow impellers located in the draft-tube (Fig. 1) and aeration confined to the annular zone, potentially overcomes some of the limitations of both the conventional stirred and the airlift vessels. This hybrid bioreactor has a highly directional flow pattern similar to that of an airlift device but it can achieve greater rates of fluid circulation than are possible in conventional airlift reactors. Highly directional and enhanced circulation of fluid means an improved capability for suspending solids and reduced axial gradients of concentration of nutrients and oxygen. Such gradients are known to occur in tall airlift reactors and affect performance adversely [1,6-9]. Furthermore, in the hybrid configuration, the gas is sparged in the

\footnotetext{
* Corresponding author. Tel.: +64-6-350-5934; fax: +64-6-350-5604 E-mail address: y.chisti@massey.ac.nz (Y. Chisti).
}

annular riser zone and not beneath the impeller; therefore, flooding becomes less of a concern.

In viscous aerobic fermentations the performance of airlift reactors can be significantly enhanced by installation of an axial flow impeller in the downcomer to improve the circulation of the fluid. This approach has been demonstrated with fermentations of the mycelial microfungus Neurospora sitophila [10]. It has also been found useful with less viscous yeast broths $[7,11]$. In highly viscous, non-Newtonian, broths of Saccharopolyspora erythraea, the use of a marine propeller located near the bottom of the draft-tube has been reported [6] to enhance the yield of the antibiotic erythromycin by ca $45 \%$ compared to the basic annulus-sparged airlift configuration. For similar highly viscous broths of the microfungus $N$. sitophila in annulus-sparged draft-tube reactors, Moo-Young et al. [10] had earlier established that the airlift configuration supplemented with a low-shear axial flow impeller in the draft-tube was better than the pure airlift device. Also, the airlift-impeller hybrid reactors have been confirmed as more effective aerobic bioreactors than the conventional, Rushton turbine-stirred fermenters [5,10,12].

Whereas the stirred hybrid airlift reactor has been shown to perform well, little is known about such devices compared to the knowledge base for the design of conventional stirred $[2,13]$ and airlift bioreactors $[1,5,14,15]$. This work reports on hydrodynamic and mass transfer characterization of a large $\left(>1 \mathrm{~m}^{3}\right)$ impeller-assisted airlift bioreactor. Low-power Prochem ${ }^{\circledR}$ hydrofoil impellers were used to enhance fluid circulation in the reactor. Prochem hydrofoils 


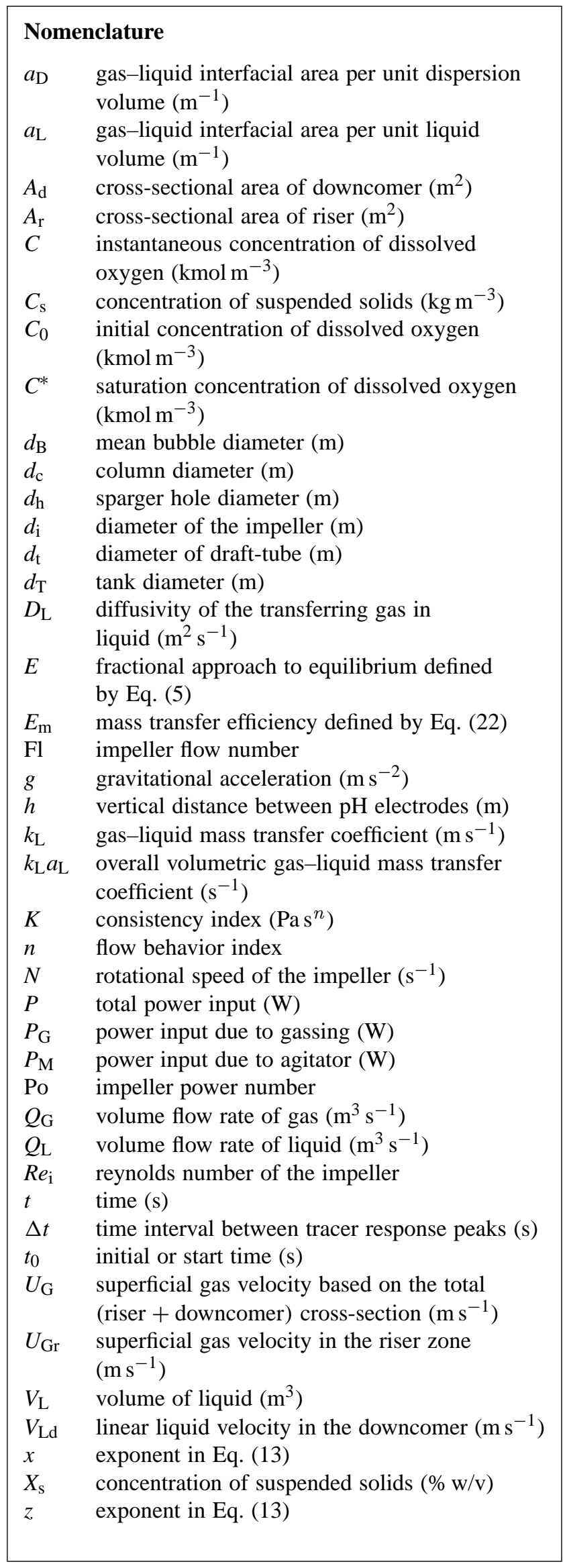

\begin{tabular}{|c|c|}
\hline \multicolumn{2}{|c|}{ Greek letters } \\
\hline$\alpha$ & Parameter in Eq. (13) \\
\hline$\gamma$ & Average shear rate $\left(\mathrm{s}^{-1}\right)$ \\
\hline$\varepsilon_{\mathrm{G}}$ & Overall fractional gas holdup \\
\hline$\varepsilon_{\mathrm{Gd}}$ & Gas holdup in the draft-tube \\
\hline$\mu_{\text {ap }}$ & Apparent viscosity of the fluid ( $\mathrm{Pas}$ ) \\
\hline & Viscosity of liquid ( $\mathrm{Pas}$ ) \\
\hline & Density of the liquid $\left(\mathrm{kg} \mathrm{m}^{-3}\right)$ \\
\hline & Interfacial tension $\left(\mathrm{N} \mathrm{m}^{-1}\right)$ \\
\hline
\end{tabular}

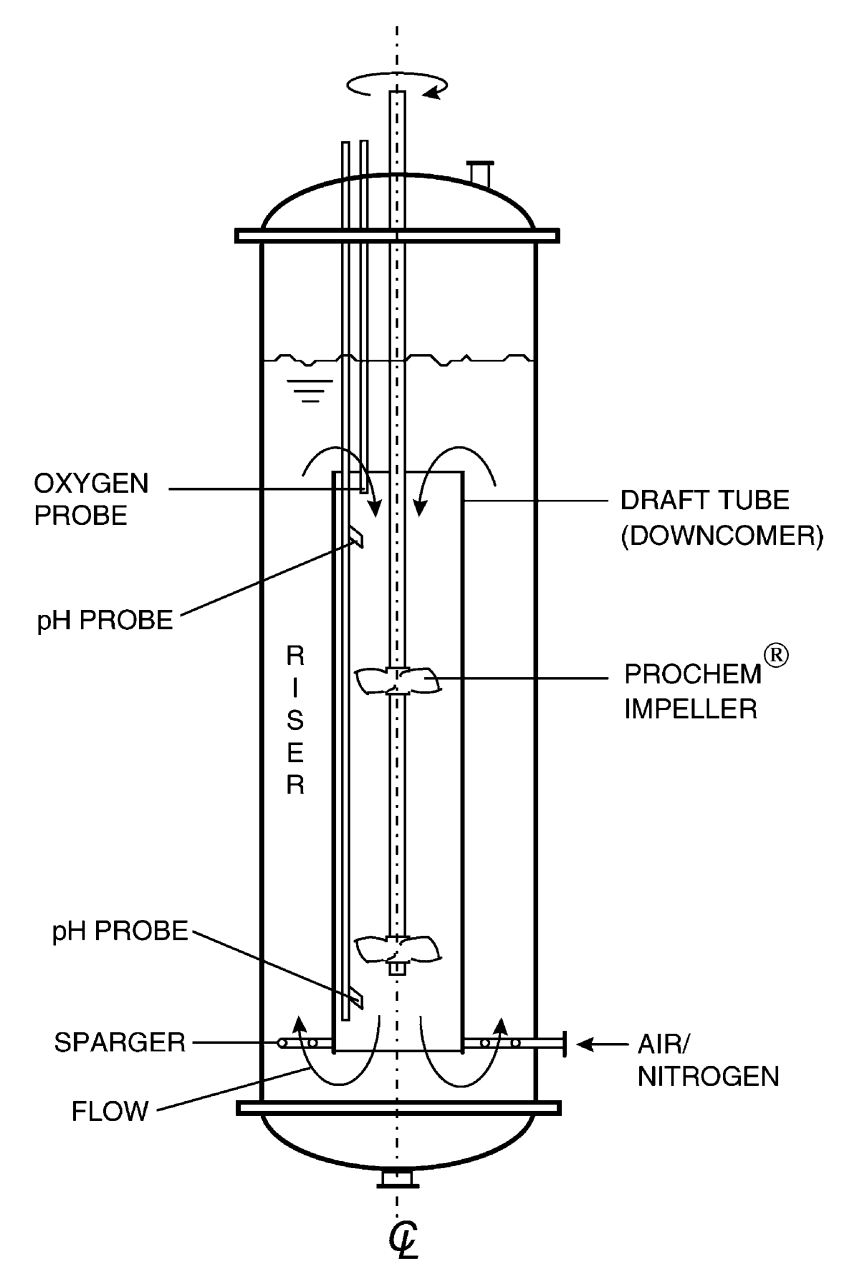

Fig. 1. The hydrofoil impeller-agitated airlift bioreactor.

have been evaluated for use in bioreactors in the past, but mostly only in the conventional baffled stirred tank configuration [16-20]. A few studies have been reported in reactors with axial flow marine propellers inside draft-tubes, but only in relatively small $(\leq 2501)$ vessels $[6,11,21,22]$.

\section{Materials and methods}

\subsection{The reactors and fluids}

Measurements were made in a concentric draft-tube bioreactor (Fig. 1) that was agitated with two identical downward 


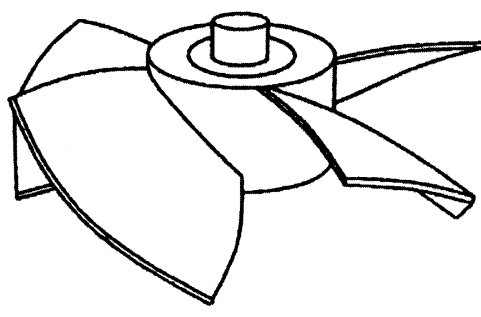

Fig. 2. The Prochem ${ }^{\circledR}$ Maxflo $\mathrm{T}$ impeller.

pumping Prochem ${ }^{\circledR}$ Maxflo T hydrofoil impellers (Fig. 2). The 5-bladed impellers, $0.32 \mathrm{~m}$ in diameter, were mounted on a $0.039 \mathrm{~m}$ diameter shaft placed at the centerline of the bioreactor vessel. The vertical distance between the impellers was $0.68 \mathrm{~m}$ and the lower impeller was located $1.02 \mathrm{~m}$ from the bottom of the tank.

The bioreactor vessel was $0.755 \mathrm{~m}$ in diameter and its overall height was $3.21 \mathrm{~m}$. The draft-tube, $0.50 \mathrm{~m}$ in internal diameter and $2.06 \mathrm{~m}$ tall, was located $0.21 \mathrm{~m}$ above the bottom of the tank. The vessel was sparged in the annular zone through a perforated pipe ring sparger (96 holes of $0.002 \mathrm{~m}$ in diameter located on two concentric sparger rings of $0.013 \mathrm{~m}$ tube diameter). The $A_{\mathrm{r}} / A_{\mathrm{d}}$ ratio was 1.27 . The working volume and the overall volume of the bioreactor were 1.10 and $1.46 \mathrm{~m}^{3}$, respectively. The bioreactor was made of stainless steel; two vertical glass windows on the side walls of the vessel allowed inspection of the liquid level. The static liquid height was $2.46 \mathrm{~m}$ in all experiments. The impellers were agitated with a $3 \mathrm{hp}$ motor $(575 \mathrm{~V}, 3$-phase, 3.9 A) and a variable speed gearbox.

A dissolved oxygen electrode (YSI 5739 dissolved oxygen and temperature probe with standard membrane; Yellow Springs Instruments, Yellow Springs, OH, USA) and two $\mathrm{pH}$ probes were located in the downcomer (Fig. 1). The oxygen electrode was positioned at a radial distance of $0.24 \mathrm{~m}$ from the centerline of the vessel and $2.15 \mathrm{~m}$ above the bottom of the tank. The vertical distance between the two identical $\mathrm{pH}$ probes was $1.39 \mathrm{~m}$; the lower probe was $0.69 \mathrm{~m}$ above the base of the tank and directly below the upper $\mathrm{pH}$ probe. The probes were placed at $0.15 \mathrm{~m}$ radial distance from the centerline of the vessel.

The reactor was sparged with air or nitrogen. The fluids used were hard tapwater, aqueous sodium chloride $(0.15 \mathrm{M})$ solution in tapwater, and 2-4\% (w/v, g/100 ml) suspensions of Solka Floc (SF) cellulose fibers in aqueous sodium chloride $(0.15 \mathrm{M})$. The slurries used were previously shown to simulate well the pulplike mycelial growth of typical fungal fermentations [1]. SF (grade KS1016; Fiber Sales \& Development, Urbana, USA) fibers had an average length of $290 \mu \mathrm{m}$ and a bulk density of $175 \mathrm{~kg} \mathrm{~m}^{-3}$. The Tyler standard screen analysis was as follows: $1.4 \%$ on 35 mesh, $2.0 \%$ on 48 mesh, $5.2 \%$ on 65 mesh, $12.6 \%$ on 100 mesh, $78.8 \%$ through 100 mesh, $39.0 \%$ on 200 mesh and $39.8 \%$ through 200 mesh. The SF slurries behaved as non-Newtonian power law fluids and their consistency $(K)$ and flow $(n)$ indices could be estimated with the following correlations:

$K=\left(8.9 C_{\mathrm{s}}^{2}-80.7 C_{\mathrm{s}}-70.4\right) \times 10^{-3}$,

$n=\left(996-44.7 C_{\mathrm{s}}+0.6 C_{\mathrm{s}}^{2}\right) \times 10^{-3}$,

where $C_{\mathrm{s}}$ is the concentration of SF solids in $\mathrm{kg} \mathrm{m}^{-3}$. Eqs. (1) and (2) are based on previously reported properties $[1,23]$; the correlation coefficients for these equations were 0.996 and 0.998 , respectively. The data used in obtaining Eqs. (1) and (2) had been measured at $20^{\circ} \mathrm{C}$ over the approximate shear rate range of $1-80 \mathrm{~s}^{-1}$ [1]. The density of the fluids ranged from 998 to $1020 \mathrm{~kg} \mathrm{~m}^{-3}$ at $20^{\circ} \mathrm{C}$. The surface tension of all fluids was $75 \times 10^{-3} \mathrm{~N} \mathrm{~m}^{-1}$, as previously reported $[1,23]$.

The SF cellulose fiber slurries in salt solutions are known to simulate well the rheological properties of the broths of mycelial fungi and filamentous bacteria [1,23] growing in the non-pelleted pulplike morphology. The cellulose fibers resemble mycelia and filaments of Penicillia, Aspergilli, Neurospora and streptomyces.

\subsection{The measurements}

Experiments were conducted batchwise with respect to the liquid or the slurry phase. All measurements were at $22 \pm$ $2{ }^{\circ} \mathrm{C}$. Air from $\sim 20 \mathrm{MPa}$ mains was supplied to the reactor through a filter, pressure regulator, flow control valve and rotameter. The flow arrangement was such that the air could be substituted instantaneously with nitrogen from cylinders.

Gas holdup, or the volume fraction of gas in dispersion, was measured by the volume expansion method [1]. The interstitial liquid velocity was measured in the draft-tube by the acid tracer technique [1]. Prior to the measurements, the liquid was freed of carbonate/bicarbonate buffering by lowering the $\mathrm{pH}$ to $<4$ and bubbling with air $\left(U_{\mathrm{Gr}}=0.085 \mathrm{~m} \mathrm{~s}^{-1}\right.$, $45 \mathrm{~min})$ while agitating $(200 \mathrm{rpm})$. After this treatment, the liquid showed no buffering over the $\mathrm{pH}$ range $(\mathrm{pH} \leq 4)$ of the measurements. For measuring the tracer response, concentrated sulfuric acid $(\sim 6 \mathrm{M}, 30 \mathrm{ml})$ was poured instantaneously on the liquid surface above the riser zone, $0.28 \mathrm{~m}$ radial distance from the centerline of the vessel. The $\mathrm{pH}$ response was followed at two downstream locations in the draft-tube. The liquid velocity $\left(V_{\mathrm{Ld}}\right)$ was calculated from the measured time interval $(\Delta t)$ between the tracer response peaks from the two $\mathrm{pH}$ electrodes and the known distance $h$ between them; thus

$V_{\mathrm{Ld}}=\frac{h}{\Delta t}$.

Concentrated sodium hydroxide was used to return the $\mathrm{pH}$ to $\sim 4$ after each measurement. A maximum of 28 measurements were taken during a day and this increased the salt (sodium sulfate) concentration in the fluid by less than $0.006 \mathrm{M}$, which did not affect the hydrodynamic properties of the hard tap water and the slurries. The mixing time was determined with the acid tracer method [1], 
as the time needed for the tracer concentration to reach $95 \%$ of its final steady-state value from the instance of tracer input.

The overall gas-liquid volumetric mass transfer coefficient $k_{\mathrm{L}} a_{\mathrm{L}}$ was measured with the well-known dynamic gassing-in method $[1,24,25]$. Two independent measurements were made simultaneously using two dissolved oxygen electrodes, located as noted in Fig. 1. In some cases, additional measurements were made with the two-probe assembly (Fig. 1) moved to the radial mid point of the riser zone and without changing the heights of the two oxygen electrodes. For the measurements, the fluid was deaerated by bubbling with nitrogen until the dissolved oxygen concentration had declined to below $5 \%$ of air saturation. The nitrogen flow was then stopped, the bubbles were allowed to disengage, a preset flow of air was now established, and the increase in dissolved oxygen concentration was followed with time until the fluid became nearly saturated with oxygen. The $k_{\mathrm{L}} a_{\mathrm{L}}$ was calculated as the slope of the linear equation

$-\ln (1-E)=k_{\mathrm{L}} a_{\mathrm{L}}\left(t-t_{0}\right)$,

where $E$, the fractional approach to equilibrium [1], is given as

$E=\frac{C-C_{0}}{C^{*}-C}$

In Eq. (5), $C^{*}$ is the saturation concentration of dissolved oxygen, $C_{0}$ the initial concentration of dissolved oxygen at time $t_{0}$ when a hydrodynamic steady-state has been reestablished ( $\leq 1 \mathrm{~min}$ ) upon commencement of aeration and $C$ the dissolved oxygen concentration at any time $t[1,25]$. The parameter $E$ is essentially the ratio of the instantaneous mass transfer rate to the maximum possible rate of oxygen transfer [1].

The specific power input due to aeration was calculated $[1,14]$ using the equation

$\frac{P_{\mathrm{G}}}{V_{\mathrm{L}}}=\frac{\rho_{\mathrm{L}} g U_{\mathrm{Gr}}}{1+A_{\mathrm{d}} / A_{\mathrm{r}}}$,

where $P_{\mathrm{G}}$ is the power input due to aeration, $V_{\mathrm{L}}$ the culture volume, $g$ the gravitational acceleration, $A_{\mathrm{d}}$ the crosssectional area of the downcomer zone and $A_{\mathrm{r}}$ the cross-sectional area of the riser zone. The superficial gas velocity $\left(U_{\mathrm{Gr}}\right)$ in Eq. (6) is based on the cross-sectional area of the riser zone. The power input due to mechanical agitation was estimated using the power number versus the impeller Reynolds number curves for the Prochem impeller [17].

For estimating the mechanical power, the impeller Reynolds number $\left(R e_{\mathrm{i}}\right)$ was defined as follows:

$R e_{\mathrm{i}}=\frac{d_{\mathrm{i}}^{2} N \rho_{\mathrm{L}}}{\mu_{\mathrm{ap}}}$,

where $d_{\mathrm{i}}$ is the impeller diameter, $N$ the rotational speed of the impeller and $\mu_{\text {ap }}$ the apparent viscosity of the fluid. The apparent viscosity in Eq. (7) was estimated with the power law equation

$\mu_{\text {ap }}=K \gamma^{n-1}$,

where the average shear rate $\gamma$ depended on the rotational speed of the impeller [26,27], as follows:

$\gamma=10 N$.

The $K$ - and $n$-values for the slurries were obtained with Eqs. (1) and (2), respectively.

The mechanical power input $\left(P_{\mathrm{M}}\right)$ related with the power number from the power curves [2,17], as follows:

$P_{\mathrm{M}}=\operatorname{Po} N^{3} d_{\mathrm{i}}^{5} \rho_{\mathrm{L}}$,

where Po is the power number. The total $P_{\mathrm{M}}$ was twice the value calculated for one impeller [27]. The impeller power draw was not corrected for the presence of gas because for Prochem hydrofoils the aeration of the fluid is known to have only a marginal impact $(<5 \%)$ on the power curve relative to that in the unaerated fluid [17] when the air flow number is small. Also, the downcomer zone where the impellers were located was not directly sparged with the gas.

The total specific power input in the fluid was obtained as follows:

$\frac{P}{V_{\mathrm{L}}}=\frac{P_{\mathrm{G}}+P_{\mathrm{M}}}{V_{\mathrm{L}}}$.

In Eq. (11), $P$ is the total power input, $V_{\mathrm{L}}$ the volume of fluid, $P_{\mathrm{G}}$ the power input due to aeration and $P_{\mathrm{M}}$ the power input due to mechanical mixing.

\section{Results and discussion}

\subsection{Gas holdup}

The fractional gas holdup increased with increasing aeration and agitation rates, as shown in Fig. 3, which was typical for all the fluids used. In all cases, the holdup initially

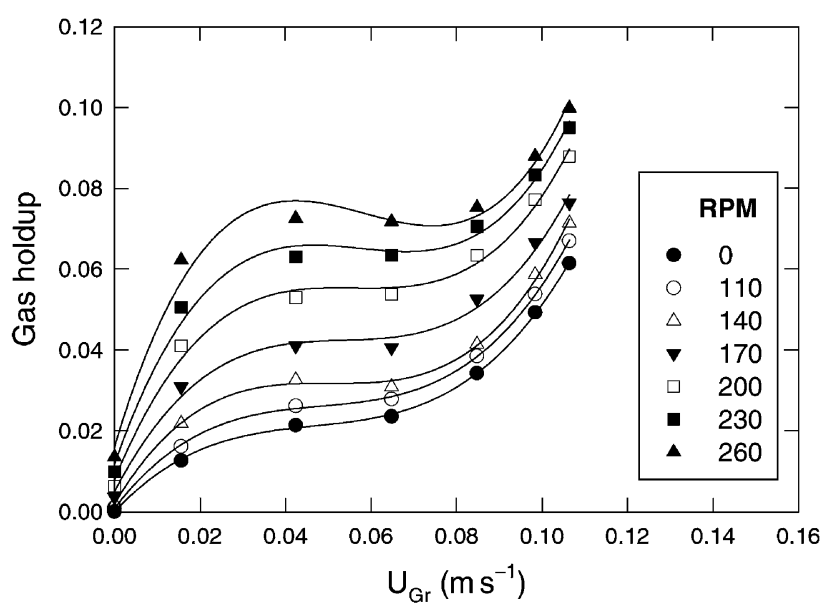

Fig. 3. Effect of impeller agitation speed and the aeration velocity on the overall gas holdup in $2 \%$ SF slurry. 


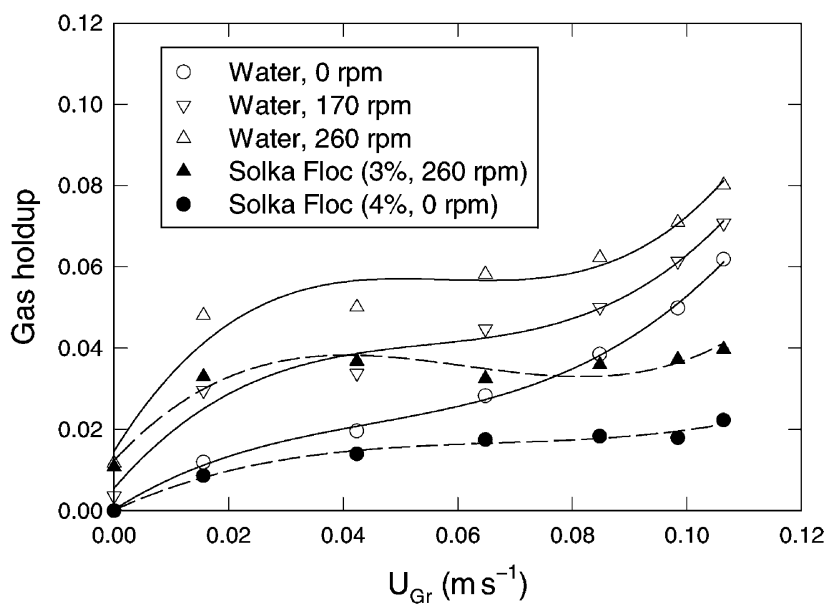

Fig. 4. Effect of the impeller agitation speed, the aeration velocity and the solids concentration on gas holdup.

rose rapidly with increasing gas velocity until an increasing rate of bubble coalescence reduced the rate of rise in holdup (Fig. 3). Bubbly flow regime in which the bubbles rose with relatively few interactions among them, persisted until a gas velocity of $<0.05 \mathrm{~m} \mathrm{~s}^{-1}$. At higher aeration rate, the coalesced bubble flow (churn turbulent flow) occurred and a rapid rise in holdup was again observed (Fig. 3) because of the formation of large spherical cap bubbles. In mechanically agitated fluids, some gas holdup persisted because of surface entrainment even in the absence of sparged aeration.

At a given aeration velocity and agitation rate, the holdup declined with increasing concentration of the cellulose fiber solids in the slurry (Fig. 4). The maximum reduction in holdup was $60 \%$ relative to the value in the solids-free system. The holdup reducing effect of solids was associated with their turbulence dampening effect. The average error in gas holdup measurements was less than $3 \%$.

\subsection{Gas-liquid mass transfer}

In the dynamic measurement of $k_{\mathrm{L}} a_{\mathrm{L}}$, the assumption regarding the state of mixedness in the reactor can influence the calculated value of the $k_{\mathrm{L}} a_{\mathrm{L}}$. A well-mixed liquid phase was assumed to exist in this work, in keeping with prior knowledge of similar systems [1]. Despite a large volume of fluid $\left(1.1 \mathrm{~m}^{3}\right)$, the assumed well-mixed state was approached closely, as confirmed in Fig. 5 where, for given agitation and aeration rates (i.e. the data within a cluster) the $k_{\mathrm{L}} a_{\mathrm{L}}$ values obtained with the dissolved oxygen probes located in widely spaced regions of the reactor (either in riser or in downcomer) showed good mutual agreement, generally within $6 \%$ of the mean value for the two locations. The data in Fig. 5 are for the air-water system under extreme states of aeration and mechanical agitation. Mixing was noticeably poorer at all gas flow rates in the airlift mode of operation (i.e. $N=0 \mathrm{rpm}$ ) compared to when the agitator was used. This is reflected in Fig. 5 where the difference between the

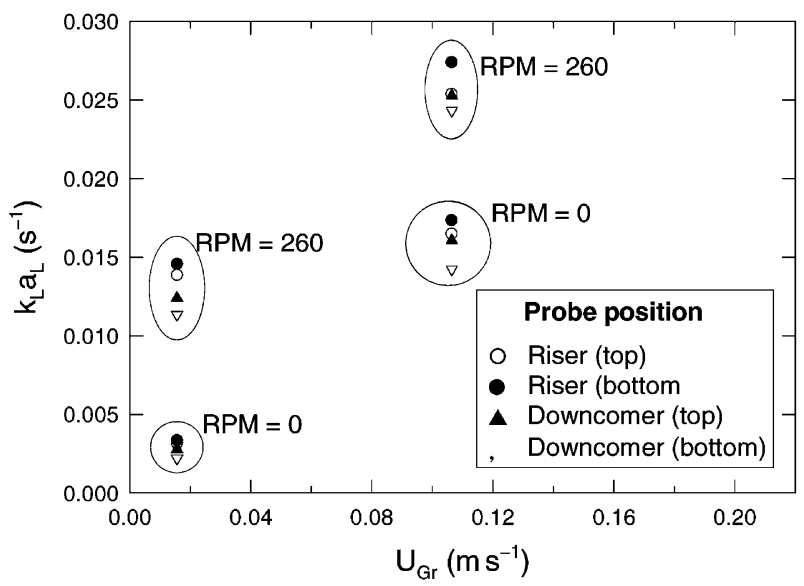

Fig. 5. Effect of the positioning of the dissolved oxygen electrode on the measured $k_{\mathrm{L}} a_{\mathrm{L}}$ for various intensities of aeration and mechanical agitation.

top and the bottom $k_{\mathrm{L}} a_{\mathrm{L}}$ values measured in the downcomer is generally greater in the absence of mechanical mixing. Because the location of the probes had a relatively minor effect on the calculated $k_{\mathrm{L}} a_{\mathrm{L}}$, the subsequent measurements were performed only at the upper location in the downcomer. The fluid mixing time (see Section 3.3) of 30-55 s was always less than $1 / k_{\mathrm{L}} a_{\mathrm{L}}$. Similarly, the response time of the dissolved oxygen electrodes $(\sim 10$ s for $63 \%$ of full scale response) was always $\leq 1 / k_{\mathrm{L}} a_{\mathrm{L}}$ and, therefore, the electrode response delays could be neglected in calculation of the $k_{\mathrm{L}} a_{\mathrm{L}}[1,28]$. The average error in the $k_{\mathrm{L}} a_{\mathrm{L}}$ measurements was $<6 \%$.

The typical dependence of the $k_{\mathrm{L}} a_{\mathrm{L}}$ on the two main operational variables (i.e. agitation speed, aeration rate) is shown in Fig. 6 for the 2\% slurry of SF. The behavior shown (Fig. 6) is generally consistent with that observed for gas holdup (Fig. 3) because holdup is the main factor that influences the gas-liquid interfacial area. The $k_{\mathrm{L}} a_{\mathrm{L}}$ value was enhanced by increasing aeration and agitation rates (Fig. 6). Increasing concentration of suspended cellulose fibers reduced $k_{\mathrm{L}} a_{\mathrm{L}}$ both in the airlift $(N=0 \mathrm{rpm})$ and the intensely agitated $(N=200 \mathrm{rpm})$ hybrid modes of operation of the reactor (Fig. 7). Similar behavior has been observed in many broths of mycelial fungi $[1,5]$.

In view of the well-known theoretical considerations [1,23], a plot of $k_{\mathrm{L}} a_{\mathrm{L}}$ against the gas holdup ratio $\varepsilon_{\mathrm{G}} /\left(1-\varepsilon_{\mathrm{G}}\right)$ is expected to be linear in any sparged bioreactor, irrespective of the fluid used and the prevailing flow regime [1]. This has been demonstrated in the past for bubble columns and airlift bioreactors [1,29]. In the mechanically agitated hybrid reactor, too, a linear dependence between $k_{\mathrm{L}} a_{\mathrm{L}}$ and the holdup ratio was observed for the full range of the aeration rates and the impeller speeds tested (Fig. 8). This behavior was seen in all the fluids examined.

As expected, the $k_{\mathrm{L}} / d_{\mathrm{B}}$ ratio $\left(d_{\mathrm{B}}\right.$ : mean bubble diameter) calculated from the measured values of $k_{\mathrm{L}} a_{\mathrm{L}}$ and the gas holdup according to a published procedure $[1,23]$, was con- 


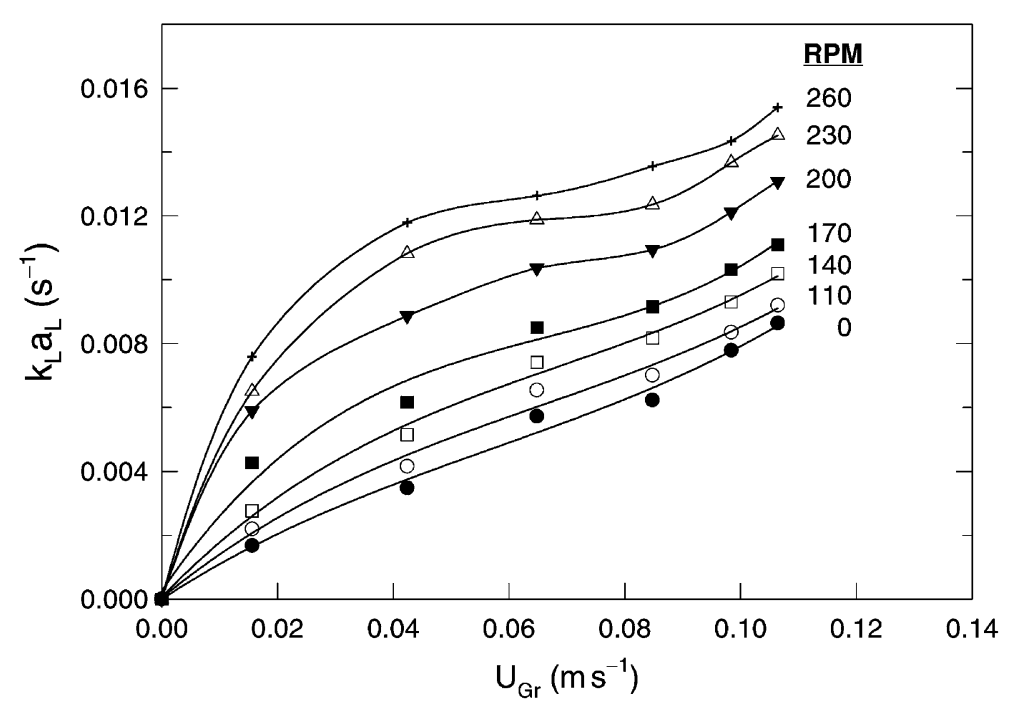

Fig. 6. Effect of agitation speed and aeration rate on $k_{\mathrm{L}} a_{\mathrm{L}}$ in $2 \%$ SF slurry.
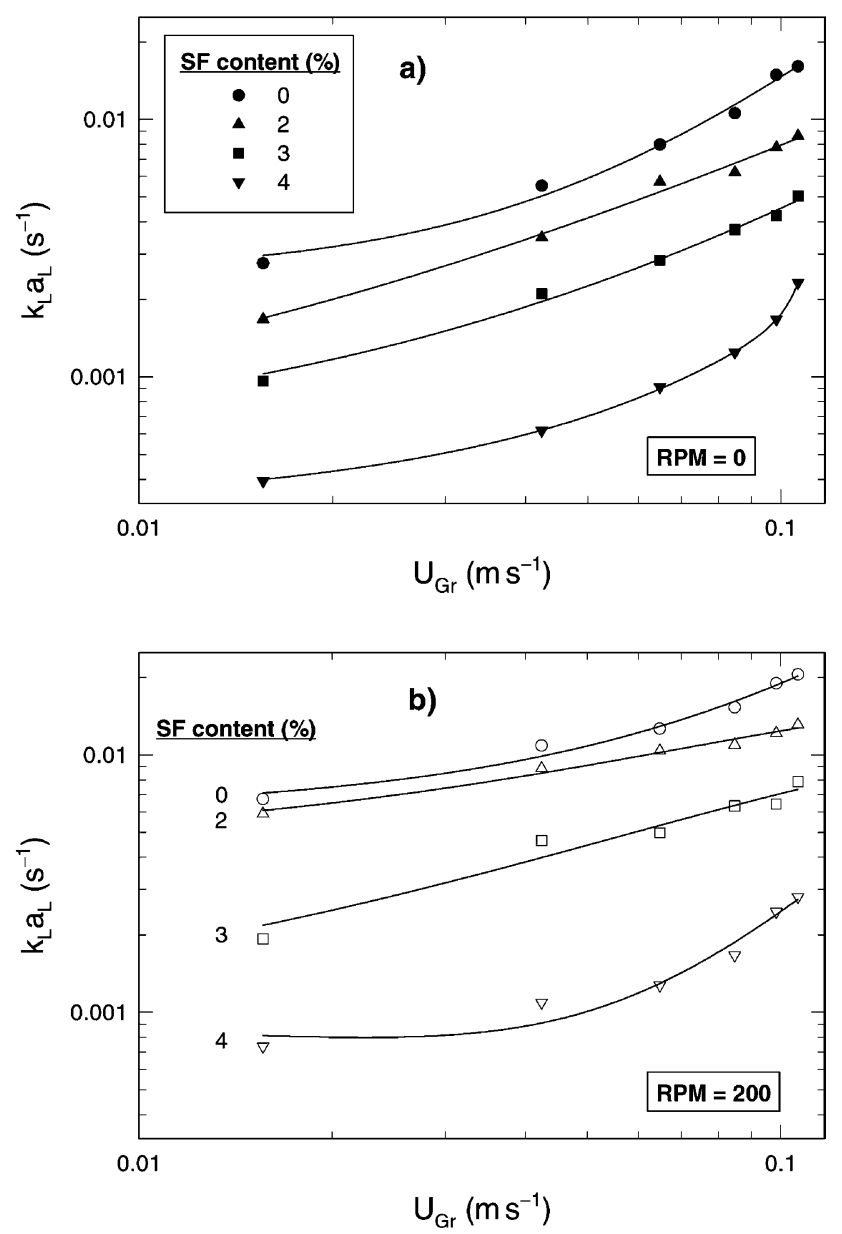

Fig. 7. Effect of the solids concentration on $k_{\mathrm{L}} a_{\mathrm{L}}$ in (a) the airlift and (b) the hybrid modes of operation of the reactor. stant irrespective of the agitation speed and the aeration rate used (Fig. 9). The pattern in Fig. 9 was representative of all the fluids tested, although the specific value of the $k_{\mathrm{L}} / d_{\mathrm{B}}$ ratio depended on the concentration of the cellulose fibers in the slurry. The mean experimental value of the $k_{\mathrm{L}} / d_{\mathrm{B}}$ ratio in $2 \%$ SF slurry was $0.0261 \mathrm{~s}^{-1}$, or within $47 \%$ of the value calculated with the independently developed empirical $[1,14,23]$ relationship

$\frac{k_{\mathrm{L}}}{d_{\mathrm{B}}}=5.63 \times 10^{-5}\left(\frac{g D_{\mathrm{L}} \rho_{\mathrm{L}}^{2} \sigma_{\mathrm{L}}}{\mu_{\mathrm{L}}^{3}}\right)^{0.5} \mathrm{e}^{-0.131 X_{\mathrm{s}}^{2}}$,

where $X_{\mathrm{s}}$ is the concentration of suspended solids in $\% \mathrm{w} / \mathrm{v}$, $D_{\mathrm{L}}$ the diffusivity of oxygen in the suspending fluid, $\sigma_{\mathrm{L}}$ the interfacial tension, $\mu_{\mathrm{L}}$ the viscosity of the liquid phase and $\rho_{\mathrm{L}}$ the density of the suspending liquid. Note that Eq. (12) was developed [1,14,23] in bubble columns and airlift reactors of entirely different geometries than the hybrid configuration of the present study.

The published correlations for $k_{\mathrm{L}} a_{\mathrm{L}}$ in mechanically agitated conventional tanks are usually of the form

$k_{\mathrm{L}} a_{\mathrm{L}}=\alpha\left(\frac{P_{\mathrm{M}}}{V_{\mathrm{L}}}\right)^{x} U_{\mathrm{G}}^{z}$,

where $\alpha, x$ and $z$ are constants for a given combination of the fluid and the geometry of the bioreactor [25,28]. An example is the following equation [30] for the air-water system:

$k_{\mathrm{L}} a_{\mathrm{L}}=\left(\frac{0.0248}{d_{\mathrm{T}}^{4}}\right)\left(\frac{P_{\mathrm{M}}}{V_{\mathrm{L}}}\right)^{0.551} Q_{\mathrm{G}}^{0.551 / \sqrt{d_{\mathrm{T}}}}$,

where $d_{\mathrm{T}}$ is the tank diameter and $Q_{\mathrm{G}}$ the product of $U_{\mathrm{G}}$ and the cross-sectional area of the reactor. A similar correlating approach was used here.

The $k_{\mathrm{L}} a_{\mathrm{L}}$ data for water in the bubble flow regime $\left(U_{\mathrm{Gr}} \leq\right.$ $0.05 \mathrm{~m} \mathrm{~s}^{-1}$ ) correlated with the equation 


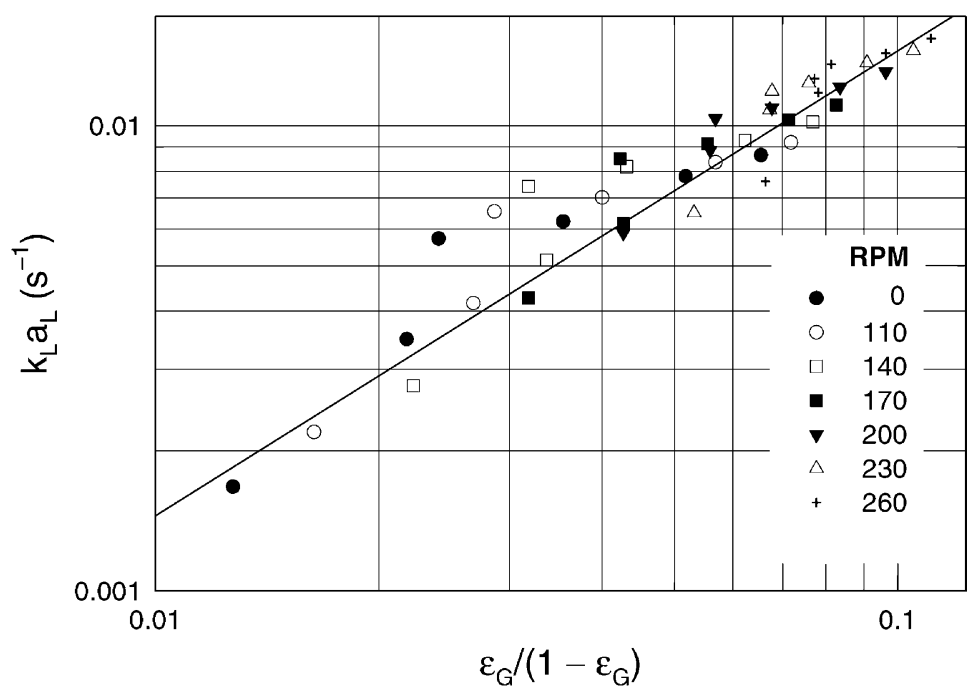

Fig. 8. The mass transfer coefficient $k_{\mathrm{L}} a_{\mathrm{L}}$ vs. $\varepsilon_{\mathrm{G}} /\left(1-\varepsilon_{\mathrm{G}}\right)$ for $2 \% \mathrm{SF}$ slurries under various conditions of agitation. The line shown has a unit slope.

$$
\begin{aligned}
k_{\mathrm{L}} a_{\mathrm{L}}= & {\left[0.04387-1.598 \times 10^{-9}\left(\frac{P_{\mathrm{M}}}{V_{\mathrm{L}}}\right)^{2.67}\right] } \\
& \times U_{\mathrm{Gr}}^{0.4060|N-4.3609|^{0.3777}}
\end{aligned}
$$

for both the airlift and the agitated-airlift modes of operation (Fig. 10). The predictions of Eq. (15) agreed with the measured data within $\pm 9.6 \%$ average deviation, or within $\pm 15 \%$ maximum deviation (Fig. 10). The data for water in the churn turbulent or the coalesced bubble flow regime $\left(U_{\mathrm{Gr}}>0.05 \mathrm{~m} \mathrm{~s}^{-1}\right)$ correlated with the equation

$k_{\mathrm{L}} a_{\mathrm{L}}=\left[0.5013-0.0769\left(\frac{P_{\mathrm{M}}}{V_{\mathrm{L}}}\right)^{0.18}\right] U_{\mathrm{Gr}}^{1.5732-0.1179 N}$

for both the airlift and the agitated-airlift modes of operation (Fig. 11). The predictions of Eq. (16) agreed with the

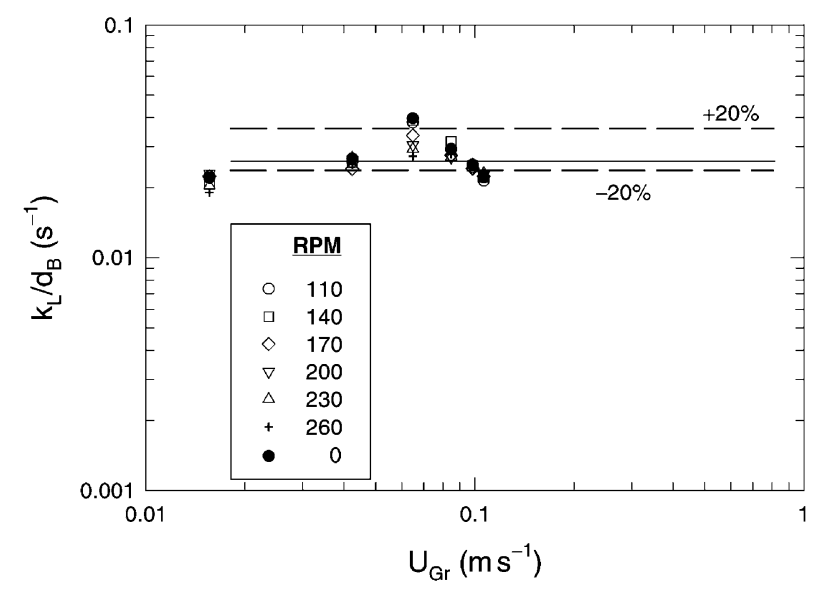

Fig. 9. Effect of aeration velocity and agitation speed on the $k_{\mathrm{L}} / d_{\mathrm{B}}$ ratio in $2 \%$ slurry of SF. The horizontal line is the average of all data. measured data within $\pm 5.6 \%$ average deviation, or within $\pm 15 \%$ maximum deviation.

In developing Eqs. (15) and (16), data for airlift modes of operation (no agitation) were first correlated in the form $k_{\mathrm{L}} a_{\mathrm{L}}=\alpha U_{\mathrm{Gr}}^{z}$. In the next stage, the superficial aeration velocity $U_{\mathrm{Gr}}$ was varied (for various fixed values of the mechanical specific power input, $P_{\mathrm{M}} / V_{\mathrm{L}}$ ) in the stirred airlift mode of operation, to obtain different measurements of $k_{\mathrm{L}} a_{\mathrm{L}}$. The resulting data were used to generate a set of $\alpha$ and $z$-values (one set for each $P_{\mathrm{M}} / V_{\mathrm{L}}$ ), by linear regression. The $z$-values were observed to depend on the agitation speed $N$ and, therefore, best-fit correlations between $z$ and $N$ were generated by regression, for the two flow regimes. The $\alpha$-value was seen to depend on $P_{\mathrm{M}} / V_{\mathrm{L}}$; hence, regression was used to determine correlations between $\alpha$ and $P_{\mathrm{M}} / V_{\mathrm{L}}$ for the two flow regimes.

A correlation for the overall volumetric gas-liquid mass transfer coefficient in the annulus sparged concentric-tube

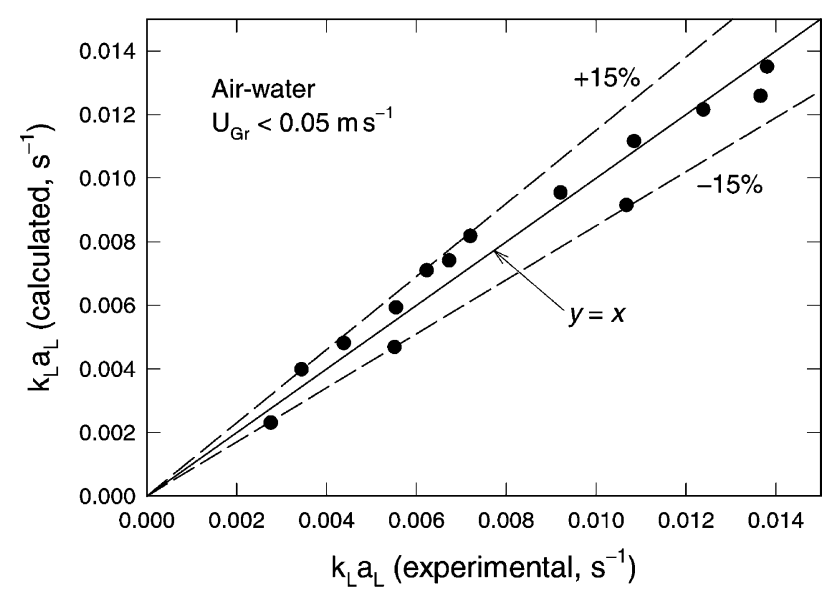

Fig. 10. Predicted (Eq. (15)) vs. measured $k_{\mathrm{L}} a_{\mathrm{L}}$ in the air-water system (bubble flow). 


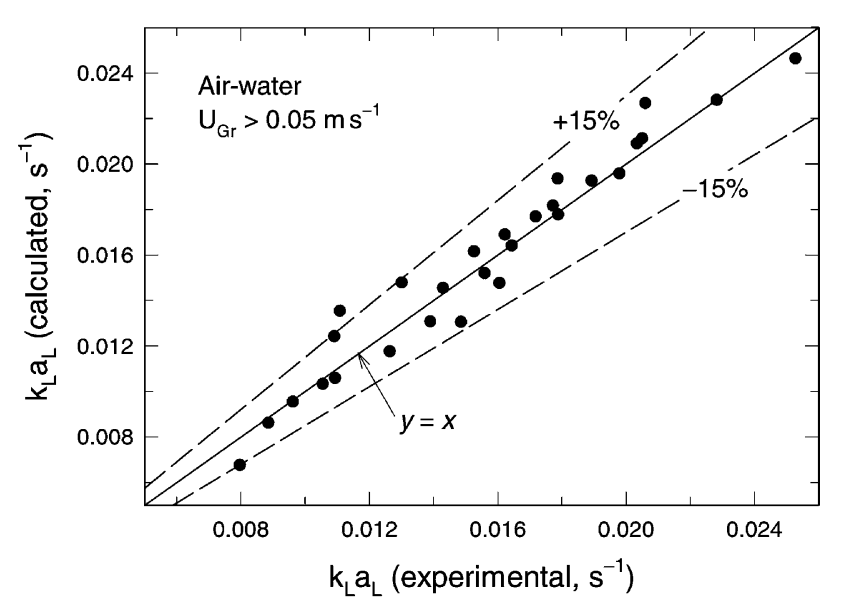

Fig. 11. Predicted (Eq. (16)) vs. measured $k_{\mathrm{L}} a_{\mathrm{L}}$ in the air-water system (coalesced bubble flow).

airlift vessels has been reported [31], as follows:

$$
\begin{aligned}
\frac{k_{\mathrm{L}} a_{\mathrm{D}} \sigma_{\mathrm{L}}}{D_{\mathrm{L}} g \rho_{\mathrm{L}}}= & 2.25\left(\frac{\mu_{\mathrm{L}}}{\rho_{\mathrm{L}} D_{\mathrm{L}}}\right)^{0.500}\left(\frac{\rho_{\mathrm{L}} \sigma_{\mathrm{L}}^{3}}{g \mu_{\mathrm{L}}^{4}}\right)^{0.136} \\
& \times\left(\frac{d_{\mathrm{h}}}{d_{\mathrm{c}}}\right)^{-0.0905} \varepsilon_{\mathrm{G}}^{1.26}
\end{aligned}
$$

where the overall mass transfer coefficient $\left(k_{\mathrm{L}} a_{\mathrm{D}}\right)$ depends on factors such as the gas holdup $\varepsilon_{\mathrm{G}}$, the gravitational acceleration $g$, the surface tension $\sigma_{\mathrm{L}}$, the viscosity $\mu_{\mathrm{L}}$ of the liquid phase, the density $\rho_{\mathrm{L}}$ of the liquid phase, the diffusivity $D_{\mathrm{L}}$ of oxygen in the liquid, the diameter $d_{\mathrm{c}}$ of the reactor column and the diameter $d_{\mathrm{h}}$ of the sparger holes. Eq. (17) was developed for the following range of variables: $3.71 \times 10^{2} \leq \mu_{\mathrm{L}} / \rho_{\mathrm{L}} D_{\mathrm{L}} \leq 6.00 \times 10^{4}, 1.18 \times 10^{6} \leq$ $\rho_{\mathrm{L}} \sigma_{\mathrm{L}}{ }^{3} / g \mu_{\mathrm{L}}{ }^{4} \leq 5.93 \times 10^{10}, 0.471 \leq d_{\mathrm{t}} / d_{\mathrm{c}} \leq 0.74 \overline{3}$, $7.14 \times 10^{-3} \leq d_{\mathrm{h}} / d_{\mathrm{c}} \leq 2.86 \times 10^{-2}, 0.0302 \leq \varepsilon_{\mathrm{G}} \leq 0.305$, aspect ratio $=6-15$ and $A_{\mathrm{d}} / A_{\mathrm{r}}=0.52-1.23$. The average error in estimating the $k_{\mathrm{L}} a_{\mathrm{D}}$ with Eq. (17) was $12 \%$ for 175 measurements [31]. As shown in Fig. 12, Eqs. (15) and (16)

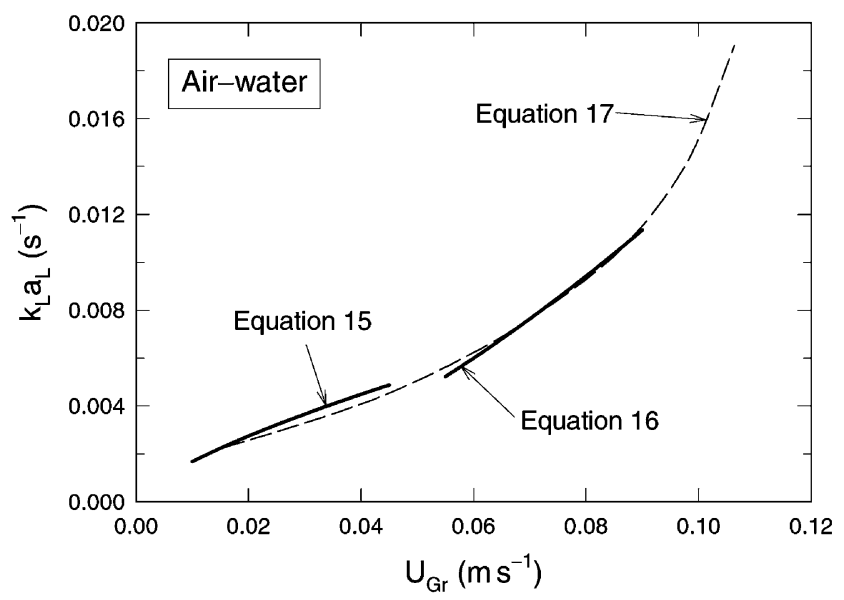

Fig. 12. A comparison of Eqs. (15)-(17) for $k_{\mathrm{L}} a_{\mathrm{L}}$ prediction in the airlift mode of operation. developed here agreed exceptionally well with Eq. (17) of Koide et al. [31] and this validates our data. Of course the earlier developed Eq. (17) does not apply to slurries and hybrid airlift reactors and so the comparison in Fig. 12 is strictly for operations in the purely airlift mode (i.e. $N=$ $0 \mathrm{rpm}$ ) with the air-water system.

Note that the overall mass transfer coefficient in Eq. (17) is given in terms of the volume of the gas-liquid dispersion and not in terms of the liquid volume. For the comparison in Fig. 12, the $k_{\mathrm{L}} a_{\mathrm{D}}$ values calculated with Eq. (17) were expressed in terms of the $k_{\mathrm{L}} a_{\mathrm{L}}$ using the following [1] exact relationship:

$k_{\mathrm{L}} a_{\mathrm{L}}=\frac{k_{\mathrm{L}} a_{\mathrm{D}}}{1-\varepsilon_{\mathrm{G}}}$.

The measured gas holdup data (see Section 3.1) were used for the correction.

The only other correlations reported for $k_{\mathrm{L}} a_{\mathrm{L}}$ in mechanically stirred airlift reactors are those of Bang et al. [21]; for the air-water system, they obtained the equation:

$k_{\mathrm{L}} a_{\mathrm{L}}=3.1 \times 10^{-3}\left[\left(\frac{P_{\mathrm{G}}}{V_{\mathrm{L}}}\right)^{0.81}+\left(\frac{P_{\mathrm{M}}}{V_{\mathrm{L}}}\right)^{0.47}\right]$.

In comparison with Eqs. (15) and (16) obtained by us, Eq. (19) produces extremely high values of $k_{\mathrm{L}} a_{\mathrm{L}}$. Also, Eq. (19) is inconsistent with Eq. (17) of Koide et al. [31]. The reasons for this disparity are apparently linked with important differences between the reactor used by us and that used by Bang et al. [21]. The latter authors employed an exceptionally small vessel $(\sim 101)$ that was sparged in the draft-tube; the $A_{\mathrm{r}} / A_{\mathrm{d}}$ ratio was only 0.69 compared to our value of 1.27; and a marine impeller pumping upward was used in the draft-tube compared to our downward pumping hydrofoil impellers.

The $k_{\mathrm{L}} a_{\mathrm{L}}$ data for all SF slurries in the bubble flow regime $\left(U_{\mathrm{Gr}}<0.05 \mathrm{~m} \mathrm{~s}^{-1}\right)$ correlated with the equation

$$
\begin{aligned}
k_{\mathrm{L}} a_{\mathrm{L}}= & {\left[\left(4.042 \times 10^{-2}-4.326 \times 10^{-7} C_{\mathrm{s}}^{3.0816}\right)\right.} \\
& \left.-1.5 \times 10^{-9}\left(\frac{P_{\mathrm{M}}}{V_{\mathrm{L}}}\right)^{0.2}\right] \\
& \times U_{\mathrm{Gr}}^{0.8442\left\{\exp -0.5\left(\left(C_{s}-27.181\right) / 13.8475\right)^{2}\right\}-0.07 N}
\end{aligned}
$$

for both the airlift and the agitated-airlift operations (Fig. 13). In the churn turbulent regime $\left(U_{\mathrm{Gr}}>0.05 \mathrm{~m} \mathrm{~s}^{-1}\right)$ the data for the slurries correlated with the equation

$$
\begin{aligned}
k_{\mathrm{L}} a_{\mathrm{L}}= & {\left[\left(0.19-4.5 \times 10^{-3} C_{\mathrm{s}}\right)-\left(1.19 \times 10^{-2}\right.\right.} \\
& \left.\left.+1.825 \times 10^{-3} C_{\mathrm{s}}+3.650 \times 10^{-5} C_{\mathrm{s}}^{2}\right)\left(\frac{P_{\mathrm{M}}}{V_{\mathrm{L}}}\right)^{0.1}\right] \\
& \times U_{\mathrm{Gr}}^{1.2025\left\{\exp -0.5\left(\left(C_{\mathrm{s}}-21.8210\right) / 20.1351\right)^{2}\right\}-0.11203 N}
\end{aligned}
$$




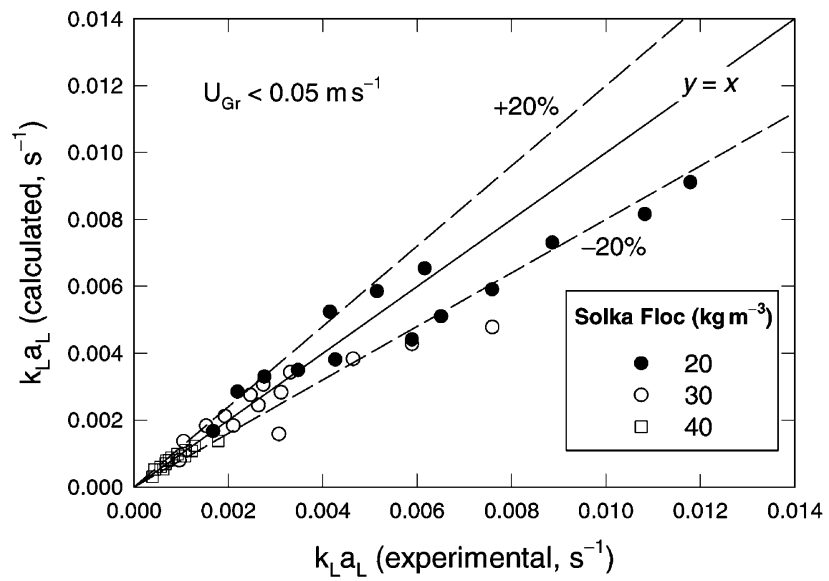

Fig. 13. Predicted (Eq. (20)) vs. measured $k_{\mathrm{L}} a_{\mathrm{L}}$ in the SF slurries (bubble flow).

for both modes of operation (Fig. 14). The predictions of Eq. (21) agreed with the measured data within $\pm 19 \%$ average deviation. The $k_{\mathrm{L}} a_{\mathrm{L}}$ diminishing effect of the solids is predominantly because of the reduction in gas holdup caused by the solids and this reduces the gas-liquid interfacial area for mass transfer. Also, an increasing concentration of the cellulose fiber solids has been shown to reduce the $k_{\mathrm{L}}$ value for a given average bubble diameter $[1,14]$.

Conventional mechanical agitation is known to enhance $k_{\mathrm{L}} a_{\mathrm{L}}$ relative to values obtained in the absence of agitation; however, the enhancement in $k_{\mathrm{L}} a_{\mathrm{L}}$ does not compensate for the increased power demand of mechanical agitation and the mass transfer efficiency is reduced in presence of agitation [1]. This also occurs in low-power agitation with hydrofoil impellers; thus, as shown in Fig. 15 for the air-water system and the $3 \%$ slurry of SF, the mass transfer efficiency $E_{\mathrm{m}}$ is lower with mechanical agitation than in purely airlift operation $(N=0 \mathrm{rpm})$. The efficiency $E_{\mathrm{m}}$ is defined as

$E_{\mathrm{m}}=\frac{k_{\mathrm{L}} a_{\mathrm{L}}}{P / V_{\mathrm{L}}}$.

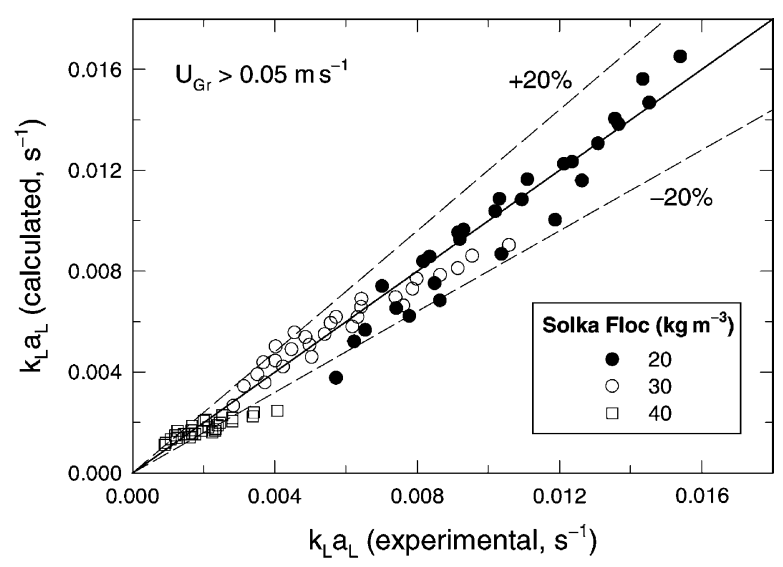

Fig. 14. Predicted (Eq. (21)) vs. measured $k_{\mathrm{L}} a_{\mathrm{L}}$ in the SF slurries (coalesced bubble flow).

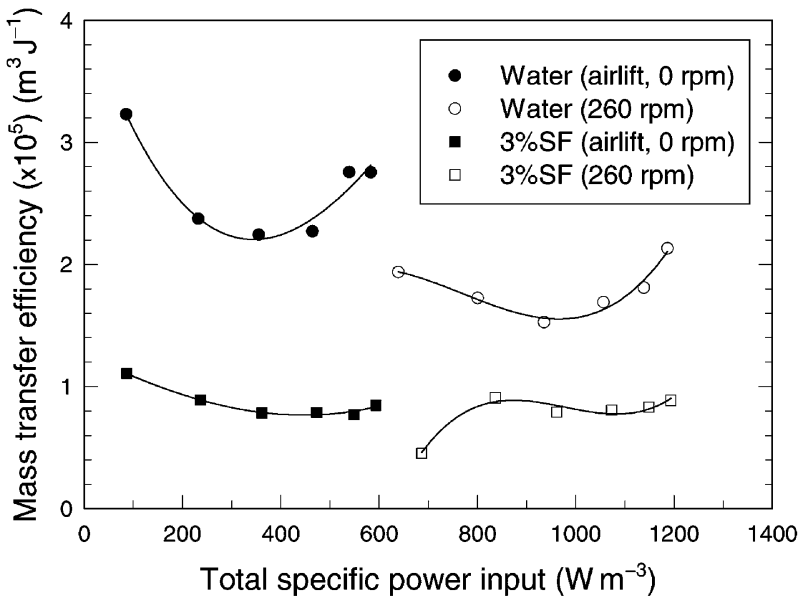

Fig. 15. Oxygen transfer efficiency vs. total specific power input under various conditions of agitation.

By multiplying the $E_{\mathrm{m}}$-value with the steady-state driving force for oxygen transfer (i.e. $C^{*}-C_{L}$ ), we can obtain the amount of oxygen transferred per unit of energy supplied.

\subsubsection{Surface aeration}

In the past, many studies characterized gas-liquid mass transfer in relatively small bioreactors $[22,30]$ in which absorption at the surface contributed significantly to the total mass transfer. Generally, no attempts were made to distinguish between the contributions of the surface and the submerged aeration. In this study, the $k_{\mathrm{L}} a_{\mathrm{L}}$ for surface aeration was measured under various conditions of agitation and without the submerged aeration. The $k_{\mathrm{L}} a_{\mathrm{L}}$ for surface aeration (air-water) correlated (Fig. 16) with the impeller speed as follows:

$k_{\mathrm{L}} a_{\mathrm{L}}=8.043 \times 10^{-6} \mathrm{e}^{1.197 N}$.

The correlation coefficient for Eq. (23) was greater than 0.999. The dependence shown in Eq. (23) is because of the combined effects of $N$ on turbulence and the fluid renewal

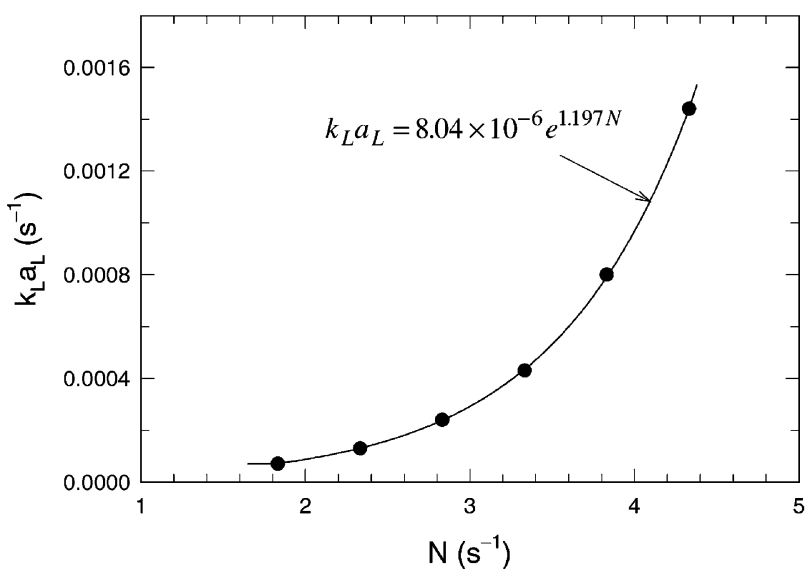

Fig. 16. Effect of impeller agitation speed on $k_{\mathrm{L}} a_{\mathrm{L}}$ for surface aeration in water. 


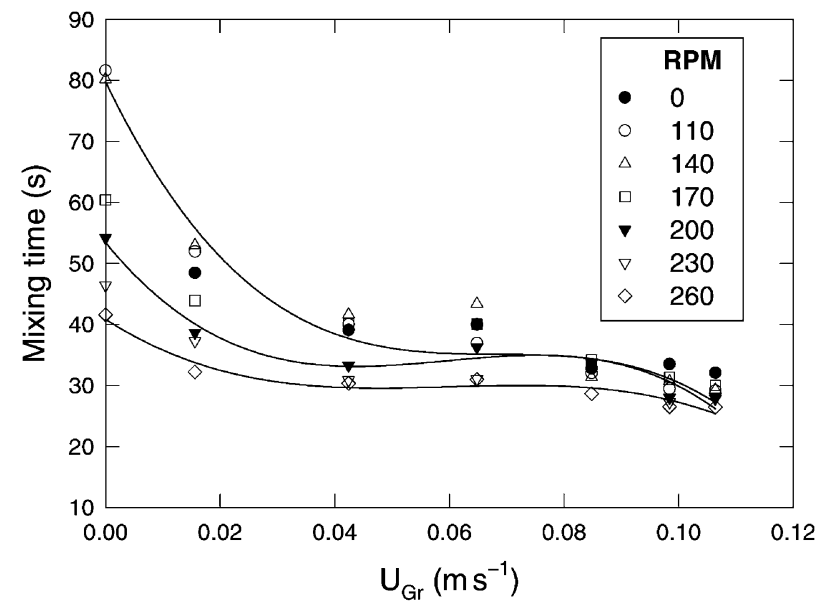

Fig. 17. Effect of the impeller agitation speed and the aeration velocity on mixing time in the $2 \%$ SF slurry.

rate at the surface. At the lowest aeration rate used $\left(U_{\mathrm{Gr}}=\right.$ $\left.0.0156 \mathrm{~m} \mathrm{~s}^{-1}\right)$, the contribution of surface aeration to the total oxygen transfer varied from 1.5 to $11.6 \%$, depending on the speed of the impeller. In this case, the ratio of the liquid surface area to the total volume was only 0.41 ; potentially, the surface can contribute more to the total mass transfer in shallow reactors such as those used for animal cell culture [25].

\subsection{Mixing and liquid velocity}

The typical variation of the mixing time with aeration and agitation rates is shown in Fig. 17. In all cases, the mixing improved with increasing rates of aeration and mechanical agitation (Fig. 17); however, the influence of aeration rate on mixing time was most pronounced only under conditions of little or no mechanical agitation. At sufficiently high aeration velocities $\left(U_{\mathrm{Gr}} \geq 0.04 \mathrm{~m} \mathrm{~s}^{-1}\right)$, the mixing times obtained in the absence of mechanical agitation were comparable to those obtained with the agitator-assisted operation. Mixing time was not sensitive to the concentration of solids over the $0-4 \%$ concentration range. The average error in the mixing time measurements was $9.4 \%$.

The linear liquid velocity in the downcomer increased with the increasing speed of the agitator but was not sensitive to the aeration rate (Fig. 18), except in the airlift mode of operation $(N=0 \mathrm{rpm})$. The fact that the liquid velocity varied little with aeration rate in mechanically agitated operation (Fig. 18) whereas at a constant agitation speed the mixing time declined with increasing rate of aeration (Fig. 17) suggests that under given conditions of mechanical mixing, the gas bubbles rising through the fluid were an important cause of mixing. Bubbling frequency increases with increasing aeration rate and the bubbles rising relative to the liquid carry in their wakes a certain amount of fluid. As noted earlier, the effect of mechanical agitation on mixing time was pronounced only at relatively low aeration rates (Fig. 17). At

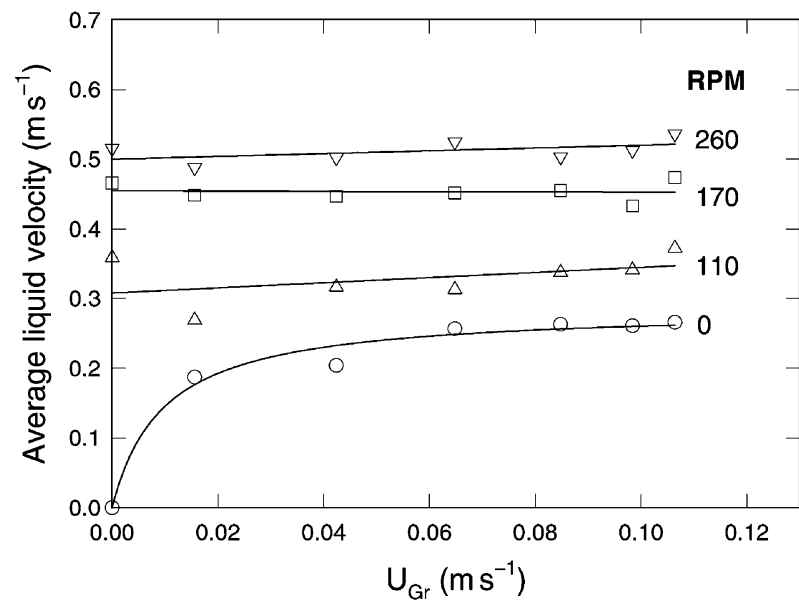

Fig. 18. Effect of the impeller agitation speed and the aeration velocity on the average liquid velocity in the downcomer (air-water).

higher aeration velocities $\left(U_{\mathrm{Gr}} \geq 0.04 \mathrm{~m} \mathrm{~s}^{-1}\right)$, rising bubbles seemed to the dominant cause of the mixing (Fig. 17).

In the air-water system, the flow was always in the developed turbulent regime whenever the agitator was used $(N \geq 110 \mathrm{rpm})$ and the impeller Reynolds number exceeded $2 \times 10^{4}$. In this regime, the impeller flow number $(\mathrm{Fl}=$ $\left.Q_{\mathrm{L}} / N d_{\mathrm{i}}^{3}\right)$ is a constant and a value of 0.82 has been reported for the flow number for the Prochem Maxflo T impeller [2]. Because of the constant flow number, the rate of pumping $\left(Q_{\mathrm{L}}\right)$ by the impeller should vary linearly with the agitation speed, as follows:

$Q_{\mathrm{L}}=0.82 d_{\mathrm{i}}^{3} N$.

The data in Fig. 18 suggest a non-linear relationship between the impeller speed and the average liquid velocity $\left(V_{\mathrm{Ld}}\right)$ measured in the draft-tube. Because the $Q_{\mathrm{L}}$ and $V_{\mathrm{Ld}}$ are related exactly [1] as follows:

$Q_{\mathrm{L}}=V_{\mathrm{Ld}} A_{\mathrm{d}}\left(1-\varepsilon_{\mathrm{Gd}}\right)$,

the discrepancy between Eq. (24) and the behavior in Fig. 18 is explained by a non-linear dependence between $N$ and the gas holdup in the downcomer, $\varepsilon_{\mathrm{Gd}}$. The average error in the liquid velocity measurements was $7.7 \%$. Unlike with the air-water system, the flow regime for mixing of the SF slurries was transitional $\left(190 \leq R e_{i} \leq 4000\right)$ because of the high apparent viscosities of the slurries.

\section{Concluding remarks}

In view of the observations discussed, the principal conclusions are as follows:

1. Use of low-power axial flow impellers in the downcomer of an airlift bioreactor can substantially enhance the rate of liquid circulation, mixing and gas-liquid mass transfer relative to operation without the agitator; however, 
the performance enhancements occur at the expense of a disproportionate increase in the power consumption.

2. Increasing concentration of the relatively light fibrous solids greatly reduces the volumetric gas-liquid mass transfer coefficient.

3. Surface aeration contributes but little to the total gas-liquid mass transfer in large bioreactors.

4. In mechanically agitated draft-tube reactors, air sparging of the riser zone may or may not improve the mixing performance, depending on the intensity of the mechanical agitation. At sufficiently high aeration rates $\left(U_{\mathrm{Gr}} \geq\right.$ $0.04 \mathrm{~m} \mathrm{~s}^{-1}$ ), whether mechanical agitation is used or not has little bearing on the mixing characteristics of the reactor.

In summary, mechanically stirred hybrid airlift reactors are well-suited for use with shear-sensitive fermentations that require good oxygen transfer and bulk mixing than can be provided by a conventional airlift reactor.

\section{Acknowledgements}

This work was partly supported by the United Nations Development Program (UNDP), Vienna and the Centro de Química Farmacéutica, Cuba. Some of the study was carried out at the University of Waterloo, Ontario, Canada.

\section{References}

[1] Y. Chisti, Airlift Bioreactors, Elsevier, New York, 1989.

[2] A.W. Nienow, Hydrodynamics of stirred bioreactors, Appl. Mech. Rev. 51 (1998) 3-32.

[3] Y. Chisti, Shear sensitivity, in: M.C. Flickinger, S.W. Drew (Eds.), Encyclopedia of Bioprocess Technology: Fermentation, Biocatalysis, and Bioseparation, Vol. 5, Wiley, New York, 1999, pp. 2379-2406.

[4] C. Nicolella, M.C.M. van Loosdrecht, J.J. Heijnen, Wastewater treatment with particulate biofilm reactors, J. Biotechnol. 80 (2000) $1-33$.

[5] Y. Chisti, Pneumatically agitated bioreactors in industrial and environmental bioprocessing: hydrodynamics, hydraulics and transport phenomena, Appl. Mech. Rev. 51 (1998) 33-112.

[6] D.J. Pollard, A.P. Ison, P.A. Shamlou, M.D. Lilly, Reactor heterogeneity with Saccharopolyspora erythraea airlift fermentations, Biotechnol. Bioeng. 58 (1998) 453-463.

[7] A.B. Russell, C.R. Thomas, M.D. Lilly, Oxygen transfer measurements during yeast fermentations in a pilot scale airlift fermenter, Bioprocess. Eng. 12 (1995) 71-79.

[8] F. Camacho Rubio, J.L. Garcia, E. Molina, Y. Chisti, Steady state axial profiles of dissolved oxygen in tall bubble column bioreactors, Chem. Eng. Sci. 54 (1999) 1711-1723.

[9] F. Camacho Rubio, J.L. Garcia, E. Molina, Y. Chisti, Axial inhomogeneities in steady-state dissolved oxygen in airlift bioreactors: predictive models, Chem. Eng. J. 84 (2001) 43-55.

[10] M. Moo-Young, Y. Chisti, D. Vlach, Fermentation of cellulosic materials to mycoprotein foods, Biotechnol. Adv. 11 (1993) 469-479.

[11] D.J. Pollard, A.P. Ison, P.A. Shamlou, M.D. Lilly, Influence of a propeller on Saccharomyces cerevisiae fermentations in a pilot scale airlift bioreactor, Bioprocess. Eng. 16 (1997) 273-281.

[12] M. Moo-Young, Y. Chisti, Considerations for designing bioreactors for shear-sensitive culture, Biotechnology 6 (11) (1988) 1291-1296.
[13] S. Nagata, Mixing Principles and Applications, Wiley, New York, 1975.

[14] Y. Chisti, M. Moo-Young, Airlift reactors: characteristics, applications and design considerations, Chem. Eng. Commun. 60 (1987) 1195-1242.

[15] J.C. Merchuk, M. Gluz, Bioreactors, air-lift reactors, in: M.C. Flickinger, S.W. Drew (Eds.), Encyclopedia of Bioprocess Technology: Fermentation, Biocatalysis and Bioseparation, Vol. 1, Wiley, New York, 1999, pp. 320-353.

[16] E.D. Eliezer, Power absorption by new and hybrid mixing systems under gassed and ungassed conditions, in: C.S. Ho, J.Y. Oldshue (Eds.), Biotechnology Processes Scale-up and Mixing, American Institute of Chemical Engineers, New York, pp. 22-30, 1987.

[17] G.J. Balmer, I.P.T. Moore, A.W. Nienow, in: C.S. Ho, J.Y. Oldshue (Eds.), Aerated and unaerated power and mass transfer characteristics of Prochem agitators, Biotechnology Processes Scale-up and Mixing, American Institute of Chemical Engineers, New York, 1987, pp. 116-127.

[18] K. Gbewonyo, D. Dimasi, B.C. Buckland, Characterization of oxygen transfer and power absorption of hydrofoil impellers in viscous mycelial fermentations, in: C.S. Ho, J.Y. Oldshue (Eds.), Biotechnology Processes Scale-up and Mixing, American Institute of Chemical Engineers, New York, 1987, pp. 128-134.

[19] N.G. Özcan-Taskin, A.W. Nienow, Mixing viscoelastic fluids with axial flow impellers: flow fields and power consumption, Trans. Inst. Chem. Eng. 73 (1995) 49-56.

[20] B.H. Junker, M. Stanik, C. Barna, P. Salmon, B.C. Buckland, Influence of impeller type on mass transfer in fermentation vessels, Bioprocess. Eng. 19 (1998) 403-413.

[21] W. Bang, I. Nikov, H. Delmas, A. Bascoul, Gas-liquid mass transfer in a new three-phase stirred reactor, J. Chem. Technol. Biotechnol. 72 (1998) 137-142.

[22] W. Bang, A.-M. Duquenne, H. Delmas, A. Bascoul, Effet d'un agitateur mécanique sur l'hydrodynamique et le transfert de matière gas-liquide en réacteur gazosiphon [Effect of a mechanical agitator on hydrodynamics and gas-liquid mass transfer in an airlift reactor], Can. J. Chem. Eng. 77 (1999) 1105-1112.

[23] Y. Chisti, M. Moo-Young, Hydrodynamics and oxygen transfer in pneumatic bioreactor devices, Biotechnol. Bioeng. 31 (1988) 487494.

[24] B. Bandyopadhyay, A.E. Humphrey, H. Taguchi, Dynamic measurement of the volumetric oxygen transfer coefficient in fermentation systems, Biotechnol. Bioeng. 9 (1967) 533-544.

[25] Y. Chisti, Mass transfer, in: M.C. Flickinger, S.W. Drew (Eds.), Encyclopedia of Bioprocess Technology: Fermentation, Biocatalysis and Bioseparation, Vol. 3, Wiley, New York, pp. 1607-1640, 1999.

[26] A.B. Metzner, R.E. Otto, Agitation of non-Newtonian fluids, AIChE J. 3 (1957) 3-10.

[27] Y. Chisti, M. Moo-Young, Fermentation technology, bioprocessing, scale-up and manufacture, in: V. Moses, R.E. Cape, D.G. Springham (Eds.), Biotechnology: The Science and the Business, 2nd Edition, Harwood, New York, 1999, pp. 177-222.

[28] K. Van't Riet, Review of measuring methods and results in nonviscous gas-liquid mass transfer in stirred vessels, Ind. Eng. Chem. Proc. Des. Dev. 18 (1979) 357-364.

[29] W.A.M. Bakker, M. den Hartog, J. Tramper, C.D. de Gooijer, Oxygen transfer in a multiple air-lift loop reactor, Bioprocess. Eng. 12 (1995) 167-172.

[30] K. Chandrasekharan, P.H. Calderbank, Further observations on the scale-up of aerated mixing vessels, Chem. Eng. Sci. 36 (1981) 819 823.

[31] K. Koide, H. Sato, S. Iwamoto, Gas holdup and volumetric liquid-phase mass transfer coefficient in bubble column with draught tube and with gas dispersion into annulus, J. Chem. Eng. Jpn. 16 (1983) 407-413. 